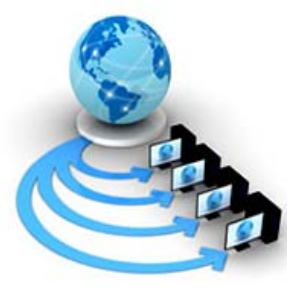

Volume 9, No. 3, May-June 2018

International Journal of Advanced Research in Computer Science

RESEARCH PAPER

Available Online at www.ijarcs.info

\title{
RESEARCH PAPER ON INTELLIGENT FARMING FOR FARMERS USING CONTROL SYSTEM IN IOT
}

\author{
Manju More E \\ Asst. Prof School of C \& IT \\ REVA UNIVERSITY \\ BANGALORE,INDIA
}

\begin{abstract}
Farmers are facing huge problem to manually water the plants. We help them to water the plants and check the humidity and moisture in the soil, air automatically. The aim of this paper is to help the farmers in their daily life to monitor the moisture of soil, humidity of air, light intensity around the crops for its better growth. Therefore we propose an intelligent farming system (IF) to improve the process of production in planting. IF composes of two main parts that is a sensor system and a control system. In this paper, we focus on the control system part which works based on watering and roofing systems of an outdoor farm based on the statistical data sensed from the sensor systems .A set of decision rules is applied based on the data sensed, is developed automatically to make a decision on whether watering and roofing system should be on or off. We also provide the options for users to manually control the watering and roofing systems by using mobile application and from web server by monitoring the sensed data.
\end{abstract}

Keywords - Intelligent farming, Temperature Sensor, Moisture Sensor.

\section{INTRODUCTION}

Internet plays a great role in people's daily activities which is used widely to connect people together, connect people with devices, or connect devices with devices. In an electronics device, it is embedded by software and sensors for communication and to exchange data with other devices and people[1]. When millions of devices are connected together through the Internet, this is called Internet of Things (loT). loT encompasses many new intelligent concepts for using in the near future such as smart home, smart city, smart transportation, and smart farming.[3].Agriculture is a process for preparing the raw materials for food that we eat daily. People in this globe lead their vegetarian life through growing eatables in farm, this habit is inherited from their ancestors. Now a days farming has been improved by

all the technology available in the world. Farming is becoming more and more advanced as the technology grows. There are tractors to cultivate the land, harvesters, drilling gadgets, drip and sprinkler systems for irrigation purposes and so on. We are implementing a technology for developing an "IOT Based Intelligent Farming" where farmers can rest from their troubles such as watering the plants when there is necessary and to stop it when the soil moisture is already wet by checking the soil moisture content[2][3]. This paper includes helping farmers to check for the humidity, and light intensity for the better growth of the plants. All this is done with the help of sensors that show us the readings in our website and mobile app.

\section{METHODOLOGY}

The sensor subsystem is a set of tools and sensors that are connected to a microcontroller board called Arduino board. Sensors are used to measure essential values of the planting process including temperature, humidity, moisture and light intensity. The values that is sensed are uploaded to the server by using a Wi-Fi module integrated Arduino board. On another part, the control subsystem is used to control the roofing subsystem and watering subsystem. The roofing and watering subsystems can be automatically open or close according to the decision from our proposed decision tree model[1]. Also, the roofing and watering subsystems can be manually controlled by a user via our mobile application[3] We also have a notification system which is used to provide the user the current farming status and also ask for the response from the user to an events like when the plants need water and the temperature is tending to high. If the user does not have any response within a limited time. The system will pump the water automatically, when the moisture sensor is

kept in the soil senses less amount of moisture content in the soil. In the same way, when the light intensity is less the roof 
opens and closes when the light intensity is too high. As explained the whole project can be controlled through a website manually, which contains the readings of Moisture, Light Intensity, Temperature, Humidity. The network connection should be high to run the project, as it runs on WiFi module.[1]

\section{RESULTS OF ANALYSIS}

The user can automatically operate the watering and roofing systems via our developed web application and monitor the current status of the plot. The web application has three main parts as follows: a user can see historical sensed data from the plot, a user can monitor plants status data and manually operate watering and roofing systems and a user can check the current and forecasted weather[1][3].

Acquiring data from sensors is a stage used to sense raw data from sensors which has its own method to convert the raw data to voltage value.. The raw data from the sensors ranges between 0 and 1023[1].

Our control system acquires the weather data, including historical, current, and forecasted weather, from Openweathermap.com to use as the conditions for making a decision. A user can see the weather information via the mobile application[4]. The historical weather data is used to model a decision tree for predicting the weather condition as "no rain", "rain” and "heavy rain”.

Based on this information, we have set up rules for making a decision in our control system on whether watering and roofing system should be on or off. Moreover, we have also provided functions for users to manually control the watering and roofing systems via our mobile application.

\section{CONCLUSION}

We have proposed a control system for an intelligent farming for an outdoor farming, called IF. To make a decision, the model requires two important information pieces which are the sensed data from the sensors in the plot and the weather condition.

\section{FUTURE SCOPE}

Our future aim is to monitor the type of soil we used for cropping, and check whether the soil is suitable for specific climatic conditions.. We can also enhance our idea to find out which type of water is suitable for the specific soil and monitor the changes that occurs in the crop.

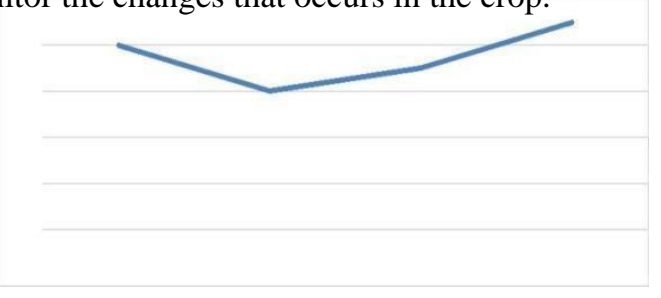

\section{REFERENCES}

[1] Sherine M. Abd EL-Kader, Basma M. Mohammad EL-Basioni Precision farming solution in Egypt using the wireless sensor network technology, Egyptian Infonnatics Jounal, 14, 3, 221-223

[2] Ilan H. (2014), International Dairy Nutrition Symposium, smart Farming; Technological Solutions

[3] for Large Herds Retrieved from http:/www.wageningenur.niQin Z. (2016).

[4] Precision agriculture technology for crop farming. Taylor \& Francis Group, LLC.Grewal, Mohinder S. Kalman filtering: Theory and practice. 2nd ed. New York: John Wiley, 2001

[5] 4.Paul R. Wonning. Gardeners Guide to Growing Cabbage in the Vegetable Garden: Mossy Feet Books, 